\title{
KONTRIBUSI PERMAINAN MATEMATIKA KREATIF DAN KEMAMPUAN NUMBER SENSE TERHADAP HASIL BELAJAR MATEMATIKA SISWA SEKOLAH DASAR
}

\author{
Frida Marta Argareta Simorangkir \\ Surel: fridasimorangkir86@gmail.com
}

\begin{abstract}
ABSTRAK
Tujuan penelitian ini untuk menguji dan menganalisis kontribusi permainan matematika kreatif dan kemampuan number sense terhadap hasil belajar siswa Sekolah Dasar. Penelitian ini adalah penelitian kuantitatif korelasional dengan populasi sebanyak 63 orang, sampel sebanyak 23 orang yang diperoleh dengan cara random. Instrumen yang digunakan adalah angket permainan matematika kreatif dan tes uraian untuk mengukur kemampuan number sense dan hasil belajar matematika siswa. Hasil penelitian sebagai berikut : (1) semua siswa tidak memiliki kepekaan yang baik mengenai bilangan, hubungan antar bilangan, operasi bilangan, hubungan antar operasi bilangan beserta sifat-sifatnya dan berfokus pada penggunaan perhitungan prosedural. Siswa dengan kemampuan number sense yang baik akan mampu memanfaatkan pengetahuannya tentang bilangan dalam pemecahan masalah matematika, (2) terdapat kontribusi positif permainan matematika kreatif terhadap hasil belajar siswa sebesar 0,416 atau 41,6\% sisanya yaitu 58,4\% dipengaruhi variabel lain di luar variabel yang diteliti dalam penelitian ini.
\end{abstract}

Kata Kunci: Permainan Matematika Kreatif, Kemampuan Number Sense, Hasil Belajar Matematika

\section{PENDAHULUAN}

Sebagian besar siswa mengalami kesulitan dalam memahami materi-materi matematika di Sekolah Dasar. Hal ini dikarenakan kurangnya pemahaman mereka terhadap konsep dasar bilangan beserta operasinya, khususnya bilangan bulat. Pilmer (2008) mengungkapkan bahwa kemampuan number sense setiap siswa berbeda karena number sense berkembang seiring pengalaman dan pengetahuan siswa yang didapatkan dari pendidikan formal maupun informal. Pada dasarnya kemampuan number sense merupakan kemampuan yang bisa dilatih pada setiap anak. Seorang anak tidak terlahir dengan membawa kemampuan number sense, tetapi para pendidik yang harus menggali dan diharapkan bisa meningkatkan kemampuan number sense siswa selama proses pembelajaran, terutama kemampuan number sense mereka dalam memecahkan masalah matematika.

Penelitian yang dilakukan oleh Aunio, Niemivirta, Hautamaki, Luit, Shi \& Zhang (2006) menunjukkan bahwa number sense dapat membantu memudahkan

Prodi Matematika Fakultas Keguruan dan Ilmu Pendidikan Universitas Katolik Santo Thomas Sumatera Utara 
anak dalam kegiatan operasional kuantitas dan sistem bilangan. Pernyataan dari penelitian tersebut menyiratkan bahwa number sense memiliki pengaruh yang besar terhadap peningkatan pemahaman peserta didik dalam pembelajaran matematika. Dapat dikatakan bahwa kemampuan number sense merupakan landasan atau fondasi awal dalam keterampilan dan penguasaan konsep-konsep matematika pada jenjang yang lebih tinggi.

Salah satu upaya meningkatkan kemampuan number sense siswa adalah menciptakan suasana belajar yang menarik dan menyenangkan. Pembelajaran akan efektif jika siswa diberi kesempatan untuk merencanakan dan menggunakan cara belajar yang mereka senangi supaya siswa dapat memahami dengan baik materi yang sedang dipelajari. Penggunaan metode yang tepat dapat membantu siswa untuk lebih mudah memahami materi yang disampaikan guru. Metode permainan dalam matematika merupakan salah satu alternatif untuk diterapkan dalam pembelajaran matematika. Sebagaimana pendapat Ruseffendi (1991) menyatakan bahwa metode permainan dalam matematika memiliki manfaat untuk: 1) menimbulkan dan meningkatkan minat, 2) menimbulkan sikap positif terhadap matematika, 3) mengembangkan konsep, 4) latihan keterampilan, 5) hiburan.

Permainan dalam matematika dapat digunakan sebagai pendekatan untuk menumbuhkan minat dan respon positif terhadap pembelajaran matematika. Namun demikian tidak selamanya permainan membuahkan hasil yang diharapkan. Menurut Ruseffendi (1991) agar permainan matematika mengenai sasaran hendaknya guru memperhatikan hal-hal berikut : (1) Waktu penggunaannya tepat, (2) Sesuai dengan tujuan serta (3) Cara penggunaannya tepat.

Salah satu permainan matematika kreatif adalah catur kuta bali. Permainan (game) catur kuta bali merupakan kependekan dari catur kurang tambah bagi kali. Permainan ini membutuhkan kemampuan dasar operasi hitung kurang, tambah, bagi dan kali pada bilangan bulat. Permainan (game) catur kuta bali dapat dijadikan alternatif untuk diterapkan dalam pembelajaran matematika karena dapat menanamkan kemampuan bernalar, melatih kecepatan berpikir dan meningkatkan kemampuan number sense siswa sehingga hasil belajar matematika siswa akan meningkat.

\section{METODE PENELITIAN}

Penelitian ini dilaksanakan selama 3 bulan di SD Swasta Sinar Pembaharuan Hidup Tanjung Mulia Medan. Sampel dalam penelitian ini adalah siswa kelas IV SD Swasta Sinar Pembaharuan Hidup Tanjung Mulia Medan. Jenis penelitian yang digunakan adalah penelitian ini adalah kuantitatif korelasional dengan menggunakan analisis regresi linier sederhana dan ganda. Adapun variabel yang diukur dalam penelitian ini yaitu variabel bebas berupa permainan matematika kreatif dan kemampuan number sense siswa. Variabel terikat berupa hasil belajar matematika siswa. Teknik pengumpulan data dalam penelitian ini 
yaitu angket permainan matematika kreatif dan tes uraian untuk mengukur kemampuan number sense dan hasil belajar matematika siswa. Angket yang digunakan dalam penelitian ini menggunakan skala Likert. Soal tes kemampuan number sense dan hasil belajar matematika siswa terdiri dari 5 soal berbentuk uraian yang memuat materi operasi pada bilangan.

\section{HASIL PENELITIAN DAN PEMBAHASAN}

\section{a) Uji Regresi Linier Sederhana}

Regresi linier sederhana didasarkan pada hubungan fungsional satu variabel independen (X) adalah kemampuan number sense siswa dengan satu variabel dependen (Y) yaitu hasil belajar matematika siswa. Hasil pengolahan data dengan bantuan Software SPSS 15.0 for Windows dapat dilihat pada Tabel 1 berikut:

Tabel 1 Analisis Regresi Linier Sederhana Kemampuan Number Sense Siswa dan Hasil Belajar Matematika

Coefficients(a)

\begin{tabular}{|ll|r|r|c|c|r|}
\hline \multirow{2}{*}{$\begin{array}{l}\text { Mode } \\
1\end{array}$} & \multicolumn{2}{|c|}{$\begin{array}{c}\text { Unstandardized } \\
\text { Coefficients }\end{array}$} & $\begin{array}{l}\text { Standardized } \\
\text { Coefficients }\end{array}$ & $\mathrm{t}$ & \multicolumn{1}{c|}{ Sig. } \\
\cline { 3 - 7 } & \multicolumn{1}{c|}{$\mathrm{B}$} & Std. Error & Beta & $\mathrm{B}$ & Std. Error \\
\hline 1 & (Constant) & 78.785 & 8.793 & & 8.960 & .000 \\
& number_sense & .041 & .124 & .061 & .332 & .742 \\
\hline
\end{tabular}

a Dependent Variable: hasil_belajar

Berdasarkan Tabel 1 diperoleh persamaan regresi linier sederhana sebagai berikut:

$$
\mathrm{Y}=78,785+0,041 \mathrm{X}
$$

Dari persamaan tersebut dapat diartikan bahwa koefisien arah regresi antara variabel kemampuan number sense siswa berpengaruh positif sebesar 0,041 terhadap variabel hasil belajar matematika siswa dalam pembelajaran matematika.

Demikian juga data akan dianalisis dengan regresi linier sederhana yang didasarkan pada hubungan fungsional satu variabel independen (X) adalah penggunaan permainan matematika kreatif yaitu permaianan catur kuta bali dengan satu variabel dependen (Y) yaitu hasil belajar matematika siswa. Hasil pengolahan data dengan bantuan Software SPSS 15.0 for Windows dapat dilihat pada Tabel 2 berikut:

Tabel 2 Analisis Regresi Linier Sederhana Permainan Matematika Kreatif dan Hasil Belajar Matematika

Coefficients(a)

\begin{tabular}{|c|c|c|c|c|c|}
\hline \multirow[b]{2}{*}{$\begin{array}{l}\text { Mode } \\
1\end{array}$} & \multicolumn{2}{|c|}{$\begin{array}{c}\text { Unstandardized } \\
\text { Coefficients }\end{array}$} & \multirow{2}{*}{$\begin{array}{c}\text { Standardized } \\
\text { Coefficients } \\
\text { Beta } \\
\end{array}$} & \multirow{2}{*}{$\frac{\mathrm{t}}{\mathrm{B}}$} & \multirow{2}{*}{$\begin{array}{l}\text { Sig. } \\
\text { Std. } \\
\text { Error }\end{array}$} \\
\hline & B & $\begin{array}{c}\text { Std. } \\
\text { Error }\end{array}$ & & & \\
\hline (Constant) & 74.150 & 11.734 & & 6.319 & .000 \\
\hline
\end{tabular}

ISBN: 978-602-50622- 


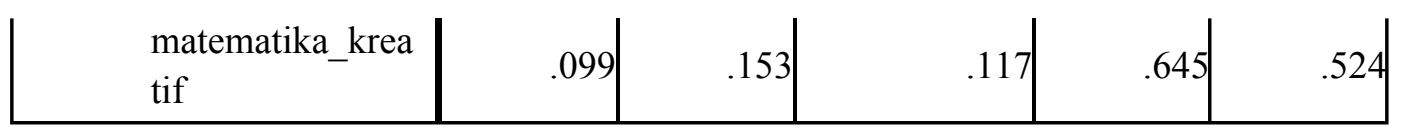

a Dependent Variable: hasil_belajar

Berdasarkan Tabel 2 diperoleh persamaan regresi linier sederhana sebagai berikut:

$$
\mathrm{Y}=74,15+0,099 \mathrm{X}
$$

Dari persamaan tersebut dapat diartikan bahwa koefisien arah regresi antara variabel penggunaan permainan matematika kreatif yaitu catur kuta bali berpengaruh positif sebesar 0,099 terhadap variabel hasil belajar matematika siswa dalam pembelajaran matematika.

\section{b) Uji Koefisien Determinasi}

Uji Koefisien Determinasi didasarkan pada hubungan fungsional satu variabel independen $(\mathrm{X})$ adalah kemampuan number sense siswa dengan satu variabel dependen $(\mathrm{Y})$ yaitu hasil belajar matematika siswa. Hasil pengolahan data dengan bantuan Software SPSS 15.0 for Windows dapat dilihat pada Tabel 3 berikut:

\section{Tabel 3 Koefisien Determinasi Kemampuan Number Sense Siswa dan Hasil Belajar Matematika Correlations}

\begin{tabular}{|ll|r|r|}
\hline & & number_sense & hasil_belajar \\
\hline number_sense & Pearson Correlation & 1 & .061 \\
& Sig. (2-tailed) & & .742 \\
& $\mathrm{~N}$ & 32 & 32 \\
hasil_belajar & Pearson Correlation & .061 & 1 \\
& Sig. (2-tailed) & .742 & \\
& $\mathrm{~N}$ & 32 & 32 \\
\hline
\end{tabular}

Berdasarkan Tabel 3 diperoleh korelasi antara variabel kemampuan number sense siswa dengan variabel hasil belajar matematika siswa dalam pembelajaran matematika sebesar 0,061. Koefisien determinasi sebesar 0,742. Hal ini berarti kemampuan number sense siswa berpengaruh sebesar 0,742 atau 74,2\% terhadap hasil belajar matematika siswa dalam pembelajaran matematika, sedangkan sisanya $25,8 \%$ hasil belajar matematika siswa dalam pembelajaran matematika dipengaruhi oleh variabel lain di luar variabel yang diteliti dalam penelitian ini.

Demikian juga analisis data dengan Uji Koefisien Determinasi didasarkan pada hubungan fungsional satu variabel independen $(\mathrm{X})$ permainan matematika kreatif yaitu catur kuta bali dengan satu variabel dependen (Y) yaitu hasil belajar matematika siswa. Hasil pengolahan data dengan bantuan Software SPSS 15.0 for Windows dapat dilihat pada Tabel 4 berikut: 
Tabel 4 Koefisien Determinasi Permainan Matematika Kreatif dan Hasil Belajar Matematika Correlations

\begin{tabular}{|ll|r|r|}
\hline & & hasil_belajar & matematika_kreatif \\
\hline hasil_belajar & Pearson Correlation & 1 & .117 \\
& Sig. (2-tailed) & & .524 \\
& $\mathrm{~N}$ & 32 & 32 \\
matematika_kreatif & Pearson Correlation & .117 & 1 \\
& Sig. (2-tailed) & .524 & \\
& $\mathrm{~N}$ & 32 & 32 \\
\hline
\end{tabular}

Berdasarkan Tabel 4 diperoleh korelasi antara variabel penggunaan permainan matematika kreatif yaitu catur kuta bali dengan variabel hasil belajar matematika siswa dalam pembelajaran matematika sebesar 0,117. Koefisien determinasi sebesar 0,524. Hal ini berarti penggunaan permainan matematika kreatif yaitu catur kuta bali berpengaruh sebesar 0,524 atau 52,4\% terhadap hasil belajar matematika siswa dalam pembelajaran matematika, sedangkan sisanya $47,5 \%$ hasil belajar matematika siswa dalam pembelajaran matematika dipengaruhi oleh variabel lain di luar variabel yang diteliti dalam penelitian ini.

\section{c) Uji Koefisien Regresi Linier Berganda}

Uji Regresi Linier Berganda didasarkan pada hubungan fungsional dua variabel independen $\left(\mathrm{X}_{1}\right)$ adalah kemampuan number sense siswa dan $\left(\mathrm{X}_{2}\right)$ adalah permainan matematika kreatif dengan satu variabel dependen (Y) yaitu hasil belajar matematika siswa. Hasil pengolahan data dengan bantuan Software SPSS 15.0 for Windows dapat dilihat pada Tabel 5 dan 6 berikut:

Tabel 5 ANOVA ANOVA(b)

\begin{tabular}{|ll|r|r|r|c|l|}
\hline Model & & $\begin{array}{r}\text { Sum of } \\
\text { Squares }\end{array}$ & Df & Mean Square & F & Sig. \\
\hline 1 & Regression & 39.477 & 2 & 19.738 & 23.352 & $.000(\mathrm{a})$ \\
& Residual & 1628.083 & 29 & 56.141 & & \\
& Total & 1667.560 & 31 & & & \\
\hline
\end{tabular}

Predictors: (Constant), matematika_kreatif, number_sense

Dependent Variable: hasil_belajar

Dari Tabel 5 ANOVA diperoleh nilai $\mathrm{F}$ sebesar 23,352 dengan tingkat signifikansi sebesar 0,000 menunjukkan bahwa ada pengaruh dari variabel $\mathrm{X}$ terhadap variabel $\mathrm{Y},(0,000<0,05)$ berarti model regresi signifikan. Demikian pula berdasarkan Tabel 6 berikut: 
Tabel 6 Coefficients Coefficients(a)

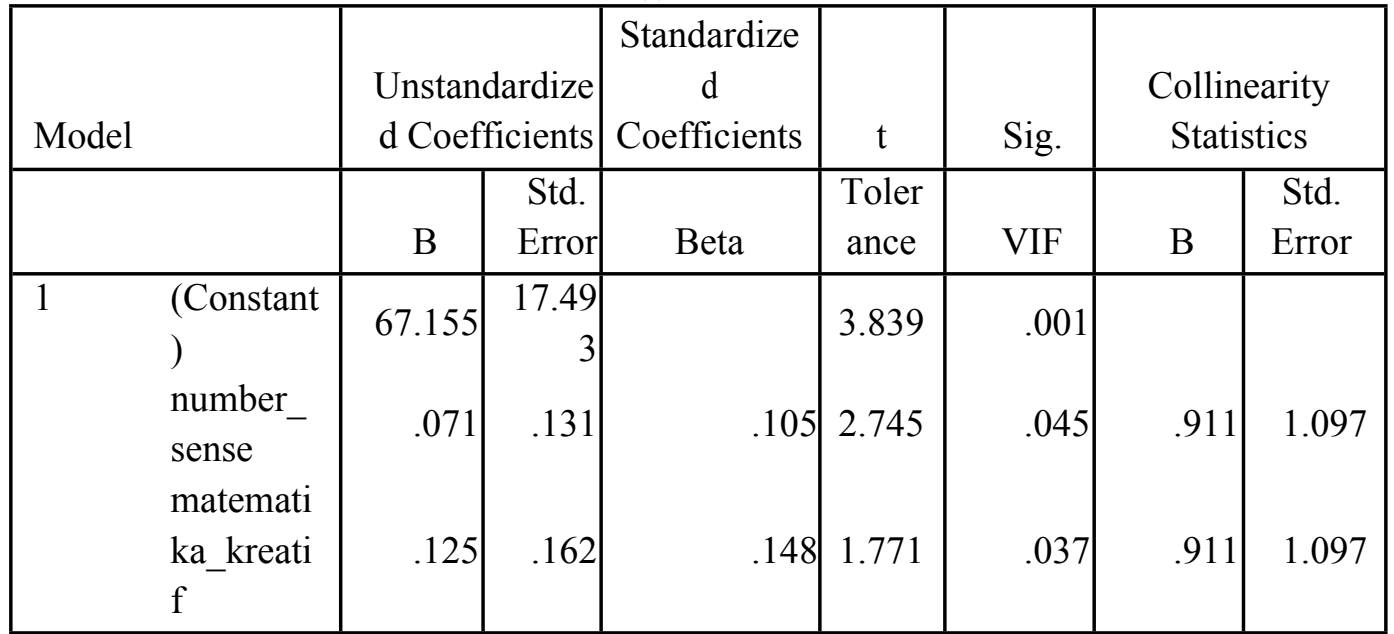

a Dependent Variable: hasil_belajar

Persamaan regresi, yaitu $\mathrm{Y}=67,155+0,071 \mathrm{X}_{1}+0,125 \mathrm{X}_{2}$. Standard Error of Estimate (SE) adalah 17,493 atau 18 unit (dibulatkan). Angka 0,105 pada Standardized Coefficients (Beta) menunjukkan tingkat korelasi antara hasil belajar matematika dan kemampuan number sense. Sedangkan 0,148 menunjukkan tingkat korelasi antara hasil belajar matematika dan permainan matematika kreatif. Nilai signifikansi kemampuan number sense sebesar 0,045 < 0,05 maka terdapat pengaruh kemampuan number sense terhadap hasil belajar matematika siswa. Nilai signifikasi permainan matematika kreatif sebesar 0,037 $<0,05$ maka terdapat pengaruh permainan matematika kreatif terhadap hasil belajar matematika siswa.

Dengan nilai df sebesar $=23-2-1=20$ pada taraf signifikansi 0,05 maka diperoleh nilai tabel $=1,724$. Nilai thitung kemampuan number sense sebesar 2,745> ttabel maka terdapat pengaruh kemampuan number sense terhadap hasil belajar matematika siswa. Nilai thitung permainan matematika kreatif sebesar 1,771 > tabel maka terdapat pengaruh permainan matematika kreatif terhadap hasil belajar matematika siswa.

Oleh karena itu, kemampuan number sense siswa perlu dilatih dalam setiap pembelajaran matematika untuk meningkatkan hasil belajar matematika siswa. Disamping itu, dalam pembelajaran matematika diperlukan permainan matematika kreatif agar siswa memiliki minat dan respon belajar yang positif terhadap pembelajaran matematika sehingga hasil belajar matematika siswa meningkat.

\section{SIMPULAN}

Berdasarkan hasil analisis dan pembahasan yang telah dikemukakan sebelumnya diperoleh beberapa kesimpulan sebagai berikut :

Diperoleh persamaan regresi linier sederhana sebagai berikut: $\mathrm{Y}=78,785+$ 0,041 X. Dari persamaan tersebut dapat diartikan bahwa koefisien arah regresi 
antara variabel kemampuan number sense siswa berpengaruh positif sebesar 0,041 terhadap variabel hasil belajar matematika siswa dalam pembelajaran matematika. Demikian pula diperoleh persamaan regresi linier sederhana sebagai berikut: $\mathrm{Y}=74,15+0,099 \mathrm{X}$. Dari persamaan tersebut dapat diartikan bahwa koefisien arah regresi antara variabel penggunaan permainan matematika kreatif yaitu catur kuta bali berpengaruh positif sebesar 0,099 terhadap variabel hasil belajar matematika siswa dalam pembelajaran matematika.

Berdasarkan hasil Uji Koefisien Determinasi diperoleh korelasi antara variabel kemampuan number sense siswa dengan variabel hasil belajar matematika siswa dalam pembelajaran matematika sebesar 0,061. Koefisien determinasi sebesar 0,742. Hal ini berarti kemampuan number sense siswa berpengaruh sebesar 0,742 atau $74,2 \%$ terhadap hasil belajar matematika siswa dalam pembelajaran matematika, sedangkan sisanya $25,8 \%$ hasil belajar matematika siswa dalam pembelajaran matematika dipengaruhi oleh variabel lain di luar variabel yang diteliti dalam penelitian ini. Demikian pula hasil Uji Koefisien Determinasi diperoleh korelasi antara variabel penggunaan permainan matematika kreatif yaitu catur kuta bali dengan variabel hasil belajar matematika siswa dalam pembelajaran matematika sebesar 0,117. Koefisien determinasi sebesar 0,524. Hal ini berarti penggunaan permainan matematika kreatif yaitu catur kuta bali berpengaruh sebesar 0,524 atau 52,4\% terhadap hasil belajar matematika siswa dalam pembelajaran matematika, sedangkan sisanya $47,5 \%$ hasil belajar matematika siswa dalam pembelajaran matematika dipengaruhi oleh variabel lain di luar variabel yang diteliti dalam penelitian ini. Berdasarkan hasil Uji Regresi Linier Berganda yaitu persamaan regresi, yaitu $\mathrm{Y}=67,155+0,071 \mathrm{X}_{1}+0,125 \mathrm{X}_{2}$. Standard Error of Estimate (SE) adalah 17,493 atau 18 unit (dibulatkan). Angka 0,105 pada Standardized Coefficients (Beta) menunjukkan tingkat korelasi antara hasil belajar matematika dan kemampuan number sense. Sedangkan 0,148 menunjukkan tingkat korelasi antara hasil belajar matematika dan permainan matematika kreatif. Nilai signifikansi kemampuan number sense sebesar 0,045 $<0,05$ maka terdapat pengaruh kemampuan number sense terhadap hasil belajar matematika siswa. Nilai signifikasi permainan matematika kreatif sebesar 0,037<0,05 maka terdapat pengaruh permainan matematika kreatif terhadap hasil belajar matematika siswa. Dengan nilai df sebesar $=23-2-1=20$ pada taraf signifikansi 0,05 maka diperoleh nilai tabel $=1,724$. Nilai thitung kemampuan number sense sebesar 2,745 > tabel maka terdapat pengaruh kemampuan number sense terhadap hasil belajar matematika siswa. Nilai thitung permainan matematika kreatif sebesar 1,771 > tabel maka terdapat pengaruh permainan matematika kreatif terhadap hasil belajar matematika siswa. 


\section{DAFTAR RUJUKAN}

Arikunto, S. 2009. Dasar-Dasar Evaluasi Pendidikan. Jakarta: Penerbit Bumi Aksara.

Aunio, dkk. 2006. Young children's number sense in Chine and Finland. Routledge: Sandivanian Journal of Educational Research, 50 (5), hlm. 483-502.

Confer, C. 2005. Teaching Number Sense in Kindergarten. United States of America: Math Solutions Publication.

Hudojo, H. 2003. Pengembangan Kurikulum dan Pembelajaran Matematika. Malang: Universitas Negeri Malang.

Munandar, S.C. Utami. 1999. Mengembangkan Bakat dan Kreativitas Anak Sekolah. Petunjuk Bagi Para Guru dan Orang Tua. Jakarta: Gramedia Widiasarana Indonesia.

National Council of Teacher of Mathematics (NCTM). 2000. Executive Summary Principles and Standars for School Mathematics. Reston, VA: NCTM.

Peraturan Pemerintah Nomor 22 Tahun 2006 tentang Standar Isi.

Pilmer, D. 2008. Number Sense. Canada: Nova Scotia School for Adult Learning. Department of Labour and Workforce Development.

Soedjadi, R. 1994. Memantapkan Matematika Sekolah sebagai Wahana Pendidikan dan Pembudayaan Penalaran, Media Pendidikan Matematika Nasional, Nomor 4 Th. 3, Surabaya: IKIP Surabaya.

TIMSS \& PIRLS International Study Center. TIMSS 2011 User Guide for the International Database Percent Correct Statistics for Released Items Mathematics - Fourth Grade. Chestnut Hill: TIMSS \& PIRLS International Study Center, Lynch Scool of Education, Boston College, dan IEA.

Russefendi. 1991. Pengantar Kepada Membantu Guru Mengembangkan Kompetensinya dalam Mengajar Matematika untuk Meningkatkan CBSA. Bandung: Tarsito.

Russeffendi. 1998. Statistika Dasar untuk Penelitian Pendidikan. Bandung: IKIP Bandung Press.

Sugiyono. 2009. Statistika untuk Penelitian. Bandung: Alfabet. 